\title{
Impact of Nursing Care Hours on Hospital Cost and Patient Satisfaction in Emergency Department
}

\author{
NASHWA M. SALAH, M.Sc.; EGLAL A. ABD EL-WAHB, D.N.Sc. and EMAN A. ETAWY, D.N.Sc. \\ The Department of Nursing Administration, Faculty of Nursing, Cairo University
}

\begin{abstract}
Background: Nurse can play an important role in helping reduce costs based on the unit census and patient acuity. Actually when nursing hours exceed the needed hours by patients, nurse managers typically are required to submit a report explaining the reason. Nurses can help make a difference in their unit budgets by not overstaffing their unit, avoiding excessive use of unscheduled leave and monitoring the use of supplies.
\end{abstract}

Aim of Study: To explore the impact of average nursing care hours on hospital cost and patient satisfaction in Emergency Department.

Material and Methods:

Design: Descriptive, exploratory, correlational design was utilized to carry out the study.

Setting: The study was conducted in Emergency Department at Soud Kafafi University Hospital.

Sample: Convenient sample included twenty-five nursing staff worked in Emergency Department and random sample of Emergency Department conscious patients, the number of study sample was one thousand patients.

Tools: Four tools were utilized for data collection, the first tool was patients triage level assessment; the second was financial record sheet, the third Nursing Care Hours Cost and the fourth was patient satisfaction questionnaire.

Results: The study findings revealed that there was highly significant statistical strong positive effect between nursing care hours and hospital cost (Adj $\mathrm{R}^{2}=.925, \mathrm{~B}=.385, p=.000$ ). While, there is no statistical significant correlation between nursing care hours with patient satisfaction.

Conclusion: The study concluded that positive effect between nursing care hours and hospital cost while no statistics effect was found between nursing care hours and patient satisfaction. Also, patients with highly acuity level consuming high nursing care hours and hospital cost.

Recommendations: It is recommended that the head nurse should measure nurses direct care hours costs per patient in order to find out patient level nursing costs/intensity, the study

Correspondence to: Dr. Nashwa M. Salah, The Department of Nursing Administration, Faculty of Nursing,

Cairo University recommend to develop strategies to measure nursing at nursepatient encounter for developing nursing business intelligence by optimizing care vs costs and matching right nurse care provider.

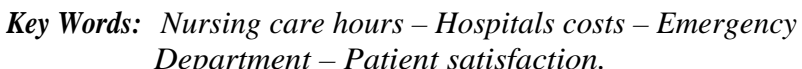

\section{Introduction}

IN an era, which the economic changes have obviously affected hospitals and hospital labor direction. Hospital executives have to answer questions regarding how to manage labor costs with better allocation of scarce resources and adjust hospital staffing to reduce expenses and improve patient care. As the economy begins to show signs of a recovery, and the pressure returns on nurse wages, attrition, and labor availability. So, executives are seeking to better understand the total cost of their labor [1]

Karen Minich-Pourshadi [2] stated that nurses shape a massive part of labor costs, they often fall under the financial microscope. Reducing these caregivers, however, can truly be detrimental to the hospital's quality of care and the patient's overall experience. The main question is how to control and potentially reduce nurse labor costs without hurting patient quality; it just requires creative staff management. Though financial leaders want to reduce costs, they fight with how to do so without the negative outcome.

Over the past few decades, measuring nursing productivity to allocate expenditure of Nursing Departments has been used Hours Per Patient Day (HPPD), but the continuous appraisal result in those hours per patient day is incompetent in measuring or estimating adequate nurse staffing [3] Welton \& Harper [4] introduced that nursing care hours is used to estimate daily charge per diem and there is no direct relationship between the 
actual nursing care hours provided to individual patients and the associated nursing care costs. Therefore patient-level nursing intensity and costs are especially unknown. So measurement of cost, quality, and intensity at the level of each nurse and patient across many different settings is vitally needed which can be used to inform operational and clinical decision making.

Pappas [5] stated that nursing time and costs vary by patient, across different care settings, and within individual patients, but there is no link between actual care, billing, and reimbursement. Hospitals and other healthcare settings that do not know their true patient-level nursing time and costs are at a distinct disadvantage in emerging payment models. The intent of healthcare reform is to optimize efficiency, productivity, and quality and reduce overall costs, and it is difficult to make optimum business decisions under these circumstances without good information. Developing accurate patient-level measures of nursing care time and costs will allow nurses and other healthcare leaders to evaluate and monitor nursing care in a more comprehensive manner [6].

Emergency Department is the most important service in hospitals in which emergency nurse playing vital role regarding safety and quality of patient care. Hospitals and health systems are under pressure to improve efficiency and reduce their healthcare costs. Increasing service pressures in the emergency department as well as costs have resulted in the executives are turning to labor costs as an opportunity to decrease their expenditures [7].

In Emergency Department Triage is the common method used for coordination of care and it is a term used to describe the rating of patients for treatment priority in Emergency Department. Triage goals are improving the safety of patients by ensuring that timing of care and resource allocation according to the degree of illness or injury. Triage is a complicated process involving decision-making under unsureness in an environment laden with emotion, driven by urgency and restrained by negotiation [8] . In the Emergency Department nurses strongly impact the quality of care because they regularly provide the major amount of patient care although nursing has always advanced care that is holistic and patient centered, it is challenging for nurses to deliver this kind of care in a fastpaced, high-intensity emergency care setting [9] .

Providing patient satisfaction in the emergency department can be difficult achievable, in the same time patients' satisfaction is one of the important indicators of emergency care quality and out-comes of health care services. Emergency Department is the main access for the major number of patients admitted to the hospital, Emergency Department is very important to increase the satisfaction and people's attitude to-ward the hospital because emergency department is the symbol of the whole hospital. Works in the Emergency Department are of a unique nature and emergency nurses are uniquely positioned to improve patient satisfaction [10].

Significance of the study: Few researches in Egypt had studied nurse's services costs in hospitals, Elsayed, Sleem \& Elsayed [11] studied nursing care hours cost in relation to nursing workload at Mansoura Emergency Hospital. Vlassoff, Abdalla \& Gor [12] estimated nurses cost within the total cost of the health system of postpartum hemorrhage in Egypt. In Emergency Department there is a variety of nursing staff with different salaries giving nursing care to Emergency Department patients with different acuity levels, with the high flow of patients in Emergency Department (40 50) per day the hospital have to cover the work over load by hiring part time nurses which lead to more hospital cost, therefore this situation need exploration. Analysis to nursing care hours in Emergency Department in relation to patient acuity level to evaluate cost benefit efficiency is needed especially with the current economic crisis. Findings of the present study will be an indicator about the adequacy of nursing care hours in relation to meet patients' needs which hopefully will be reflected positively on patient satisfaction. Furthermore study might have implications on nursing services redistribution of the available nursing staff to have maximum benefit to the hospital cost as well as avoid excessive use of extra hours cost.

\section{Material and Methods}

Design: Descriptive, exploratory, correlational design was utilized to carry out the study.

Setting: The present study was conducted in Emergency Department at the Memorial Souad Kafafi University Hospital during 2019 which has 265 total bed capacities which is affiliated to Misr University for Science and Technology. The total number of Emergency Department unit beds are 12 beds divided into three rooms, five beds for critical and serious cases in one room, five beds for examination and more stable cases in another room and two beds in the last room one bed for stitching and the second bed for casting. 
Aim of study: To explore the impact of average nursing care hours on hospital cost and patient satisfaction in Emergency Department.

\section{Research questions:}

1- What is the average cost per nursing care hours according to the patient triage level?

2- What are the patient's satisfaction levels in Emergency Department?

3- What are the relationships between nurse's personal characteristics and their nursing care hours for patients with the same triage level?

4- What is the impact of nursing care hours on hospital cost and patient satisfaction?

\section{Sample:}

1- Convenient sample of nursing staff who were available, and accept to participate in the study and their numbers were $(n=25)$ with different degree of nursing qualifications baccalaureate degree, diploma of technical institute of nursing and nursing diploma degree and different nursing staff position staff nurses, charge nurses and head nurse.

2- Random sample of Emergency Department patients have different acuity triage level. Their number were $(n=1000)$ of male and female patients that was asked by investigator of their satisfaction.

Data for the present study were collected by using the following tools:

First tool:

Patients triage level sheet:

Which is considering one of the hospital patient forms designed by hospital that used in Emergency Department to classify patients upon admission in Emergency Department according to their triagelevel and including two parts:

1 st part: Patient personal characteristics as (age, gender, level of education, date, time, mode of arrival to emergencydepartment (walking, ambulance, wheel chair, by car,...), patient vital data as patient vital signs conscious level, circulation assessment, airway assessment, glasco coma scale, triage category level (I, II, III, IV) which level (I) Serious and critical life-threatening patients, level (II) Patients with non-life-threatening injuries, but whourgently require treatment, level (III) Patients minor injury can wait for treatment and level (IV) Non urgent patients.

2nd part: Triage assessment of emergency patient history, as allergies, past medical history (diabetes mellitus, hypertension, oncology, cardiac, asthma, psychiatry, surgeries) as well as pain assessment (site, intensity, duration, frequency) nursing care needed, needed investigation. Investigator added one item to this tool (time in) which starting when assigned nurse handling patient and (time out) when patient discharged from Emergency Department. By this tool the investigator can get the patient personal characteristics, patient triage level and the time difference between time in and time out which is considering the direct nursing care hours given to patient.

\section{Second tool:}

Financial record sheet: It was developed by investigator which including emergency nurse's financial information as nurse hour salary cost, education level, years of experience all this data obtained from Human Resource Department in the hospital. By this tool the investigator can use nurse salary hour cost to estimate patient direct nursing care cost by multiplying it with the time difference between time in and time out she got from 1 tool well as using nurse's personal characteristics to measure its relation with patient nursing cost and patient satisfaction.

\section{Third tool:}

Nursing care hours cost sheet: It was developed by investigator that include patient variables as (age, sex, patient triage level) and nurse variables (age, gender, education level, years of experience, nursing care hours given to patient) from patient triage level and nurse hour cost, the investigator can use it to estimate nursing care hours cost for each patient in emergency.

\section{Fourth tool:}

Patient satisfaction questionnaire a modified and translated version based on HCAHPS, [13] and it modified by investigator it consists of five dimensions with 18 items to assess patient satisfaction with Emergency Department care and services. Patient satisfaction questionnaire include two parts:

1st part: Personal characteristics data of patients consists of age, gender and level of education.

2 nd part: Patient satisfaction questionnaire: It consisted of five dimensions which contained 18 items, 1 dimension related to patient satisfaction during patient arrival to Emergency Department, 2nd dimension about patient satisfaction regarding nursing care received in Emergency Department, 3 rddimension about satisfaction regarding pain management, 4 th dimension about satisfaction with Emergency Department environment and 5 th di- 
mension about satisfaction regarding discharge from Emergency Department.

The scoring system: The first and 2 nd dimensions each one of them have two questions were granted (2) point for the answer yes and (1) for no answer, $3 \mathrm{rd}$, and 4 th dimensions are 4-point Likert scale on satisfactions, (4) always, (3) usually, (2) sometimes, and (1) never. The 5 th dimensions are 4-point Likert scale on satisfactions 1 st question, (4) excellent, (3) very good, (2) good, and (1) poor and 2 nd question (4) definite yes, (3) may be yes, (2) may be no, and (1) definite no.

\section{Tools validity:}

Content validity was checked before pilot study by a group of experts is consulted to identify tools content and validity. Five experts checked tools, three professors from Nursing Administration Department at Faculty of Nursing, Cairo University and two medical mangers were working in Emergency Department in two different hospitals.

\section{Pilot study:}

A pilot study was conducted on $(10 \%)$ of the total sample that to test their applicability, to measure their reliability and to estimate the time consumed in carrying out nursing care for different triage level of patients and for measuring their satisfaction. The investigator carried out the collection with the randomly selected one hundred patients from emergency department to assess to what extent these tools are understandable and fulfill their purpose of development. Pilot sample was not included in study sample.

\section{Tools reliability:}

Was measured by using the Alpha Cronbach's coefficient test which equal to $(97.0 \%)$ for patient satisfaction questionnaire sheet of pilot study.

\section{Procedure:}

Once permission was granted from Research Ethical Committee and the Nursing Administrator of the selected hospital to proceed with the prepared research, the investigator got a list of all nursing staff members who working in emergency department from human resource department which including their names, age, gender, qualifications, experience in addition to cost per hour of work for each of them, then the investigator met the unit head nurse to explain the purpose of the study and to obtain her permission to approach the participants during the three shifts and started to invite separately each participant according to their shift to participate in the study to provide an oral explanation about the purpose, nature of the study to facilitate and control data collection process, and then each participant signed a written informed consent. To assess staff nurse's adherence to their expected role regarding patient triage level during their patient delivery of care. Intermittent observation for 2-3 hours to observe nurses while manage patient according to their acuity level and to collect data in different shifts four times/week was done. Nurses use hospital format of patient assessment triage level sheet, this format includes (time in) and (time out) as added information to calculate duration of direct nursing care by each nurse. Patient triage level from patient triage assessment sheet was collected, direct nursing care time was obtained from the time difference between time in when assigned nurse start to handle the patient and patient time out when patient is going to discharge from Emergency Department, also assigned nurse name is obtained from nurse signature present on triage form. From the obtained data direct nursing care hours calculated to estimate its cost. Patient satisfaction questionnaire sheet was added to each patient triage assessment sheet and it was given to patients or their relatives by assigned nurse before patient discharge from Emergency Department to fill it. Patient characteristics were collected from patient satisfaction questionnaire sheet. All data was collected in 3 months started from beginning of Februry 2018 to end of April 2018.

\section{Statistical analysis:}

The collected data was categorized, scored, tabulated, and analyzed by computer using statistical package for social science (SPSS) Version 20. Descriptive statistics will be used in the form of frequency distribution and percentages between variables were evaluated using Pearson's correlation coefficient, significance was adopted at $p 0.05$ for interpretation of results of tests of significance.

\section{Results}

Table (1) shows that the highest percentage $(60 \%)$ of the nursing staff according to age ranged from 25-30 years old. the highest percentage (64\%) of the staff nurses of were male, while $(36 \%)$ were female. $(72 \%)$ were diploma of technical health nursing institute while the least percentage (12\%) of the staff nurses graduated from Bachelor of nursing. Regarding to years of experience the highest percentage $(60 \%)$ of the staff nurses ranged from $3<5$.

Table (2) showed that the highest percentage of patients $(66.4 \%)$ belongs to 3 rd triage level, while the lowest percentage of patients $(2.0 \%)$ 
belong to ${ }^{1 \text { st }}$ triage level. Also showed that the maximum of nursing care hours belong to $1{ }^{\text {st }}$ triage level with mean $84 \pm 63.67$, while the minimum of it belong to 4 th triage level with mean $31.4 \pm 21.9$, and the maximum of hospital nursing cost/patient belong to 1 st triage level with mean $32.1 \pm 25.45$, while the minimum of it belong to 4 th triage level with mean $12.05 \pm 8.60$.

Table (3) showed that there is highly significant strong positive correlation between nursing care hours and hospital cost, also showed insignificant correlation between nursing care hours with patient satisfaction.

Table (4) showed that the highest percentage $89.36 \%$ of patient satisfaction related to discharge from Emergency Department, while the lowest percentage $79.8 \%$ was related to pain management.

Table (5) showed that significant correlation between nurses' age and hospital cost. Also revealed that there is significant correlation between nurses' experience and hospital cost, while there is insignificance correlation between patient satisfaction and nurse's demographic variables.
Table (6) showed that highly significant statistical strong positive effect from nursing care hours on hospital cost (Adj $\left.\mathrm{R}^{2}=.925, \mathrm{~B}=.385, p=.000\right)$. Regression: Simple linear regression.

Table (1): Percentage distribution of demographic characteristic of nursing staff $(\mathrm{N}=25)$

\begin{tabular}{|c|c|c|}
\hline Personal characteristic & $\mathrm{N}$ & $\%$ \\
\hline \multicolumn{3}{|l|}{ Age: } \\
\hline $20<25$ & 7 & 28.0 \\
\hline $25<30$ & 15 & 60.0 \\
\hline $30<35$ & 2 & 8.0 \\
\hline $35<40$ & 1 & 4.0 \\
\hline Mean \pm SD & \multicolumn{2}{|c|}{$27.2 \pm 3.77$} \\
\hline \multicolumn{3}{|l|}{ Gender: } \\
\hline Female & 9 & 36.0 \\
\hline Male & 15 & 64.0 \\
\hline \multicolumn{3}{|l|}{ Level of nursing education: } \\
\hline Bachelor of nursing & 3 & 12.0 \\
\hline Diploma of technical institute of nursing & 18 & 72.0 \\
\hline Diploma of nursing & 4 & 16.0 \\
\hline \multicolumn{3}{|l|}{ Years of experience: } \\
\hline$<3$ years & 1 & 4.0 \\
\hline $3<5$ years & 15 & 60.0 \\
\hline $5<10$ years & 9 & 36.0 \\
\hline
\end{tabular}

Table (2): The average cost of nursing care hours according to patient triage level $(\mathrm{N}=1000)$.

\begin{tabular}{|c|c|c|c|c|c|c|c|c|c|c|}
\hline \multirow{2}{*}{ Variable } & \multicolumn{2}{|c|}{ Patients } & \multicolumn{4}{|c|}{ Nursing care hours/min } & \multicolumn{4}{|c|}{ Hospital nursing cost/patient } \\
\hline & $\mathrm{N}$ & $\%$ & Min & Max & Mean & SD & Min & Max & Mean & SD \\
\hline $1 \mathrm{st}$ & 20 & 2.0 & 0 & 21 & 84 & 638 & 1.88 & 75. & 32. & 25.45 \\
\hline 2 nd triage level & 165 & 16.5 & 5.00 & 240 & 54.7 & 39.24 & 2.24 & 108.00 & 26.784 & 18.12 \\
\hline 3 rd triage level & 664 & 66.4 & 2.00 & 375 & 66.4 & 40.96 & .55 & 121.38 & 21.21 & 15.23 \\
\hline 4th triage level & 151 & 15.1 & 5.00 & 120 & 31.38 & 21.89 & 2.91 & 38.84 & 12.05 & 8.60 \\
\hline
\end{tabular}

Table (3): Correlations between nursing care hours and hospital cost per hour in Emergency Department.

\begin{tabular}{lccc}
\hline Variables & $\begin{array}{c}\text { Pearson } \\
\text { Correlation }\end{array}$ & $\begin{array}{c}\text { Patient } \\
\text { satisfaction }\end{array}$ & $\begin{array}{c}\text { Nursing } \\
\text { care hours }\end{array}$ \\
\hline Nursing care hours & $r$ & -.003 & \\
& $p$ & .924 & \\
Hospital cost & $r$ & .008 & $.962^{* *}$ \\
& $p$ & .791 & .000 \\
\hline
\end{tabular}

Table (4): Mean and S.D of patient satisfaction levels in emergency room.

\begin{tabular}{lcc}
\hline Patient satisfaction dimensions & Mean \% & SD \\
\hline Arrival to emergency room & 84.09 & .63 \\
Nursing care & 87.19 & 4.03 \\
Management of pain & 79.81 & 1.68 \\
ED environment & 89.13 & 2.86 \\
Discharged from ED & 89.36 & 1.52 \\
Total satisfaction & 85.92 & 9.72 \\
\hline
\end{tabular}

Table (5): Relation between nurses demographic variables on nursing care hours, hospital cost and patients' satisfaction.

\begin{tabular}{lcccc}
\hline Demographic variables & $\begin{array}{c}\text { Pearson } \\
\text { Correlation }\end{array}$ & $\begin{array}{c}\text { Nursing } \\
\text { care hours }\end{array}$ & $\begin{array}{c}\text { Hospital } \\
\text { cost }\end{array}$ & $\begin{array}{c}\text { Patients' } \\
\text { satisfaction }\end{array}$ \\
\hline Nurses' age & $r$ & $-.021-$ & $.104^{* *}$ & $-.009-$ \\
& $p$ & .499 & .001 & .778 \\
Nurse' experience & $r$ & $-.013-$ & $.159^{* *}$ & $-.004-$ \\
& $p$ & .673 & .000 & .898 \\
Nurses' educational level & $r$ & .053 & .045 & $-.009-$ \\
& $p$ & .095 & .151 & .772 \\
\hline
\end{tabular}


Table (6): Effect of nursing care hours on hospital cost $\mathrm{N}=25$ nurses.

\begin{tabular}{lccccccc}
\hline Variable & Adjusted $\mathrm{R}^{2}$ & $\mathbf{B}$ & $\mathrm{F}$ & Std. Error & Beta & $t$ & Sig. \\
\hline (Constants) & .925 & .28 & 12493.045 & .23 & & 1.216 & .224 \\
Nursing care hours & & .385 & & .003 & .962 & 111.772 & .000 \\
\hline (Dependent): Hospital cost. & & & & & &
\end{tabular}

\section{Discussion}

Satisfaction of patient is a common way to identify nursing practices in most of the countries, by identifying the quality of nursing care services; it is a valid indicator to assess client satisfaction with the expectation regarding nursing services. Nursing care hours has been used as a standard measure in reporting hospital or unit nurse staffing and better patient satisfaction [14].

Finding of the current study revealed that the number of male nurses more than female nurses this may be due to the nature of work in emergency department need male more than female, their age ranged from 25 to 30 years and their working experience ranged from three to five years; this may be because of the most dominant average age of the nurses at the study sample ranged from 25 to 30 years. Also, nurses were employed in private hospital which the current study was carried out which nurse's retention is low. About two three of the sample participants were had diploma of technical institute of nursing; this may be due to the number of educational technical institutions graduating nurses are more than the number of faculties graduating bachelor degree nurses in Egypt, these results are not consistent with M. Fry, M. Harris [15] who reported that number of female nurses was more than three half of their study sample, and most of them their experience ranging from 5 to 10 years' experience in Emergency Department.

Results of the present study also declared that the highest percentage of patients belong to triage level III those patient are non-urgent cases can wait safely for treatment and these results are consistent with Pascasie and Mtshali [16] who reported that occupancy of the emergency center by non-urgent cases (66\%), who come directly from the community level without following any referral system and cause overcrowding at Emergency Department.

The result of the current study revealed that measuring direct nursing care cost at the patient level by using patient triage level revealed that there is variation in nursing time and costs per individual patient which the highest cost belongs to triage level (I) due to more than one nurse caring of this critical patient it could reach to four nurses as during CPR (cardiopulmonary resustation) also the highest length of nursing care hours belongs to patient triage level (I) due to this level include more serious and critical patients, these results are consistent with, A. Jenkins [17] who reported that measuring direct nursing cost per patient in the acute care setting revealed that nursing intensity and costs increased as severity of patients increased and stated that the cost per case method captured variable costs of nursing care by patient to provide a more accurate picture of true nursing costs than traditional accounting measures and nursing research based on allocated and not actual cost.

The result of the current study revealed that the highest percentage of patients are satisfied with the nursing care provided to them while only low percentage are dissatisfied with their nursing care services, these result are consistent with A. Ghafoor, Hussain, Afzal and Gillani [18] they stated that satisfaction of patients achieved when their expectation are met, their results showed that patients are overall satisfied with the nursing care which provided to them. Also, the result of the current study showed that there is highly patient satisfaction in Emergency Department for different study dimensions which is not compatible with Olaogun and Okunola [19] they stated that patients perceived the emergency nursing care in their selected studied hospitals was unsatisfactory.

This study result declared that there is insignificant correlation between patient satisfaction and nurses' personal characteristics which is not compatible with Blegen, Goode, Park, Vaughn, and Spetz [20] they found a positive effect of nurse education level on patient satisfaction when controlling for staffing levels. Also study result showed that there is insignificant correlation between nursing care hours and nurses personal characteristics while controlling triage level, this is not consistent with the findings of Aiken, et al., and Scott [21] they found that hospitals with higher proportions of baccalaureate-prepared nurses had fewer patient adverse events (such as hospitalacquired pressure ulcers and extended length of stay). Regarding to nurses' personal characteristics and hospital cost the study result showed a signif- 
icant correlation between nurses' age and hospital cost also a significant correlation between nurses' experience and hospital cost this is consist with the findings of [18] A. Jenkins who reported that significant correlation between nurses' experience as well as age and hospital cost, also this result showed insignificant correlation between nurses' education level and hospital cost which is not compatible with Nef, Al-Amin, Nogle, Maldonado [22] they found that registered nurse staffing educational levels have a significant impact on hospital financial performance in more competitive markets.

The result of the current study revealed that the correlation between nursing care hours and hospital cost is highly significance strong positive correlation these results are consistent with A. Jenkins [17] who reported that significant correlation between nursing care hours and hospital cost. Also, the result of the current study revealed that insignificance correlation between nursing care hours and patient satisfaction the results of the study were not matched with Omran, Elmolla and Abd Elaziz [23] who stated that there is statistical significant relation between patient satisfaction and nursing care of patient and stated that nurses play an important role because nurse providing patients with adequate information, advice and support around treatment is an important component of care.

\section{Conclusion:}

The study concluded that there was strong positive effect between nursing care hours and hospital cost and insignificant correlation between nursing care hours and patient satisfaction. Also, patients with highly acuity level consuming more nursing care hours and more hospital cost.

\section{Recommendations:}

Based on the findings of this study, the following recommendations are suggested:

1- Head nurse should ensure skill, experience mix in all shifts over 24 hours.

2- Head nurse should consider nurse's skill, experience and patient acuity level in distribution of patient assignment for matching right care nurse cost provider.

3- Hospital administrators should match patient nursing services pricing according to their acuity level, because the highly acuity level consuming more nursing care hours and more hospital cost.

\section{References}

1- KPMG'S U.S.: Hospital Nursing Labor Costs Study, 2017.
2- KAREN MINICH-POURSHADI, 2012: HealthLeaders Media, January 17, Financial, Management for Nurse Managers and Executives Elsevier Ebook, 2016.

3- DOUGLAS: We can do better. Nursing Economics, 32 (1): 40-1, 2014

4- JENKINS and WELTON J.M.: Measuring direct nursing costs per patient in the acute care setting. Journal of Nursing Administration, 44 (5), 257-62, 2014. Hours per patient day: Not the problem nor the solution. NURSING ECONOMIC $\$ 2015$.

5- PAPPAS S.H.: Value, a nursing outcome. Nurs. Adm. Q., 37: 122-8, 2013.

6- SHARON PAPPAS and JOHN M.: Welton, Nursing Essential to Healthcare Value, Nurse Leader June, 2015.

7- NATASHA JENNINGS, STUART CLIFFORD, JANE O'CONNELL, AMANDA R. FOX and GLENN GARDNER: The impact of nurse practitioner services on cost, quality of care, satisfaction and waiting times inthe Emergency Department, 2015.

8- ALOYCE R., LESHABARI S. and BRYSIEWICZ P.: Assessment of knowledge and skills of triage amongst nurses working in the emergency centers in Dar es Salaam, Tanzania. African Journal of Emergency Medicine, 4: 148, 2014.

9- LISA CARNAGO and MERLE: Using ways of knowing to guide emergency nursing practice Emerg. Nurs., 2015.

10- BEHZAD ZOHREVANDI and HOSNA TAJIK: Survey of Patients' Satisfaction in Emergency Department of Rasht Poursina Hospital. February 2016/Vol. 34/No, The economic value of health care data. Nurs. Adm. Q. 2013; 37: 105-8, 2014.

11- 'ELSAYED W.A., SLEEM W.F. and ELSAYED N.M.: Nursing Workload and the Cost of Nursing Care. Mansoura Emergency Hospital, 2012.

12- VLASSOFF M., ABDALLA H.A. and GOR V.: The Cost to the Health System of Postpartum Hemorrhage in Egypt, New York: Guttmacher Institute, https://www. guttmacher. Org/report/cost-of-postpartum-hemorrhage-in-egypt, 2016.

13- Hospital Consumer Assessment of Healthcare Providers and Systems (HCAHPS), ROBIN, et al.: Is a registered trademark of the Agency for Healthcare Research and Quality, a U.S. Government agency, 2013.

14- JISUN CHOI, DIANE K. BOYLE, and NANCY DUNTON: A Standardized Measures: NDNQI Nursing Care Hours IndicatorWest J. Nurs. Res. published online 2 September, DOI: 10.1177/0193945913501723, 2013.

15- MARIONHARRIS a and MARGARETFRYb: The utilization of one district hospital Emergency Department by people with Parkinson's disease. Australas Emerg Nurs J. Feb., (1): 1-5, 2017, doi: 10. 1016/j.aenj. 2016.12. 004. Pub 2017 Jan. 7. Emergency Department, Hornsby Hospital, Australia. Electronic address: Marion. Harris@ . health.nsw.gov.au. Northern Sydney Local Health District, Faculty of Health, University of Technology Sydney, Australia. Electronic address: Margaret.Fry@uts. edu.au

16- KAGOBORA PASCASIE A. and NTOMBIFIKILE GLORIA MTSHALI B.: A descriptive analysis of Emergency 
Department overcrowding in a selected hospital in Kigali, Rwanda, 2014.

17- JENKINS J.A.: Measuring direct nursing costs per patient in the acute care setting. Journal of Nursing Administration, 2014.

18- GHAFOOR* R.A.M., HUSSAIN M. and AFZAL S.A.: GILLANI, Adult Patient Satisfaction with Nursing Care, In Government Hospital Lahore, Pakistan Saudi J. Med. Pharm. Sci., Mar., Vol. 4, Iss. 3: 364-70, 2018.

19- OGUNLADE A.A., AYANDIRAN E.O., OLAOGUN A.A. and OKUNOLA I.: Perception of Emergency Nursing Care among Patients in Selected Hospitals in Oyo State Nigeria. International Journal of Caring Sciences MayAugust 2017 Volume 10 | Issue 2| 972, 2018.

20- BLEGEN M.A., GOODE C.J., PARK S.H., VAUGHN T and SPETZ J.: Baccalaureate Education in Nursing and Patient Outcomes the Journal of nursing administration
January, DOI: 10.1097/NNA. 0b013e31827f2028, Source: PubMed, 2013.

21- AIKEN, et al., 2011: SCOTT SEUNG EUN LEE and LINDA D.: Scott Hospital Nurses' Work Environment Characteristics and Patient Safety Outcomes. Western Journal of Nursing Research, Vol. 40 (1): 121-45, 2018.

22- EVERHART D., NEFF D., AL-AMIN M., NOGLE J. and WEECH- MALDONADO R.: The effects of nurse staffing on hospital financial performance: Competitive versus less competitive markets. Health Care Manage Rev., 38 (2): 146-55. doi: 10. 1097/HMR.0b013e318257292b, 2013.

23- OMRAN G.A., EL MOLLA M. and ABD EL-AZIZ M.: Quality of Nursing Care and Satisfaction for Patient under Chemotherapy Treatment at Cairo Univeristy Hospitals the Department of Medical Surgical, Faculty of Nursing, Cairo University, 2013. 


\section{تأثير الساعات التمريضية على تكلفة المستشفى ورضا المرضى فى وحدة الطوارئ}

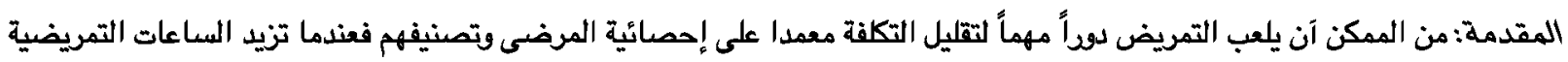

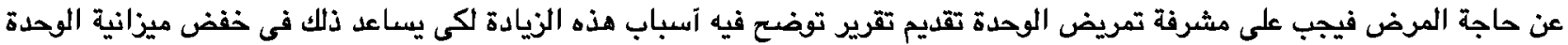

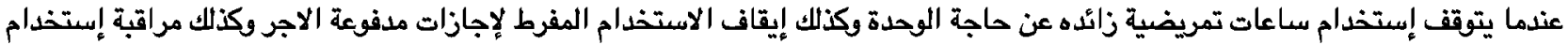
المستلزمات الخاصة بالمرضي.

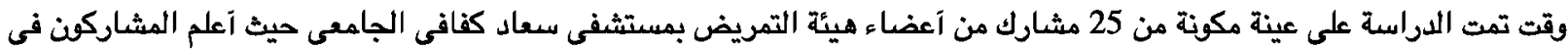

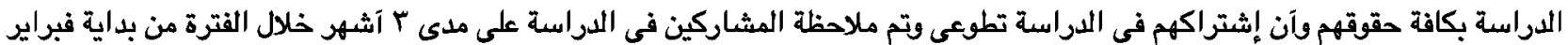

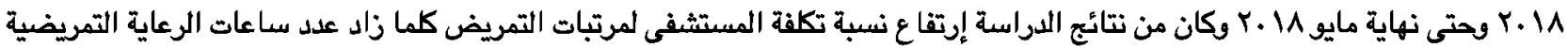

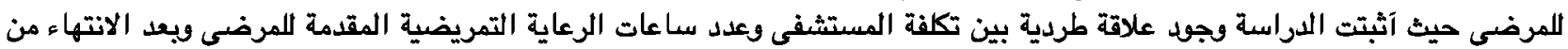

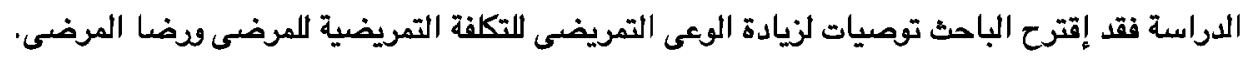

الهدف النهائى للبحث: الهدف من الدراسة هو دراسة العلاقة بين مدى تأثير الساعات التمريضية على تكلفة المستشفى ودضا المرضى

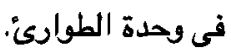

$$
\text { تصميم البحث: إستخدام منهج الارتباط الوصفى لتحقيق هدف البحث. }
$$

عينة البحث: شملت عينة البحث عدد Y ممرض فى وحدة الطوارئ وعدد آلّ مريض من مرضى الطوارئ.

$$
\text { إدارة البحت: يوجد آريع آدوات اللبحث: }
$$

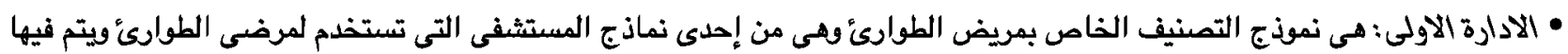

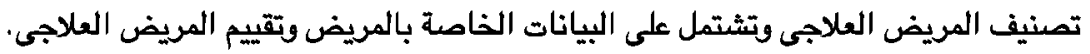

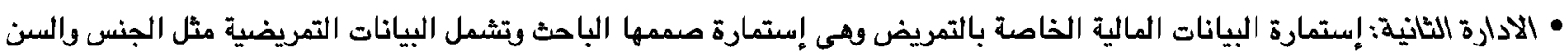

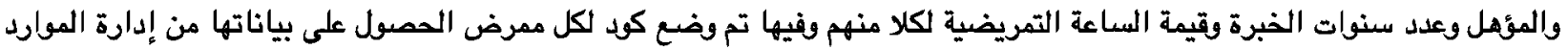
البشرية بالمستشفى.

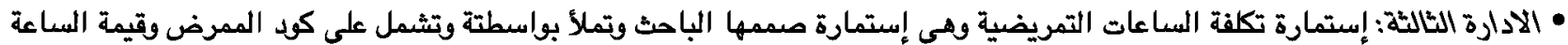

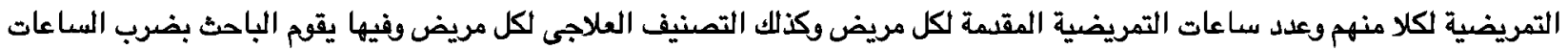

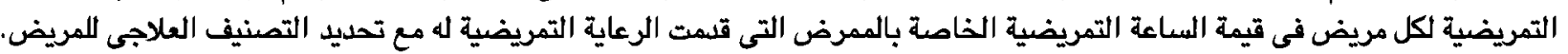

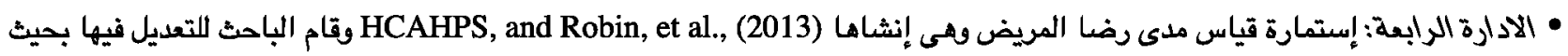
تحتوى على خمس آبعاد بهم ثُمانية عشر عنصر التقييم رضا المشا المرضى في وحدة الطوارئ.

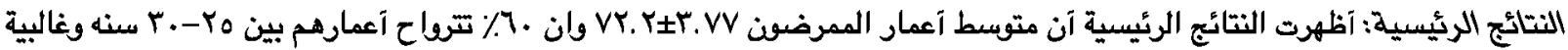

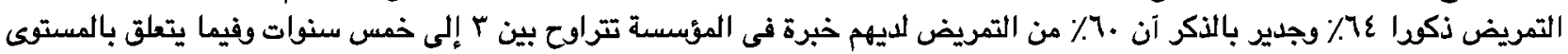

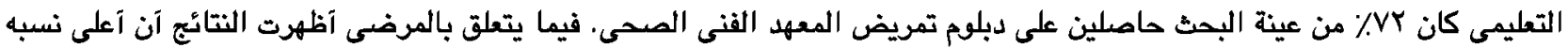

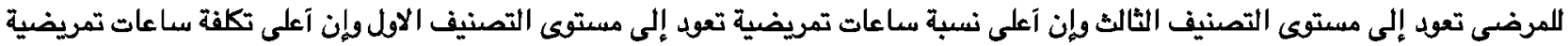
تنتمى لمستوى الاول.

وآيضاً آظهرت الدراسة آنه توجد علاقة إرتباطية إيجابية قوية بين عدد الساعات التمريضية وتكلفة المستشفى وكنالك يوجد علاقة إيجابية

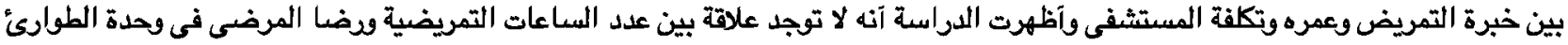

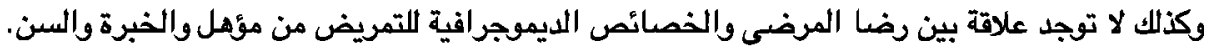

$$
\text { التوصيات: بناء على نتائج هذه الدراسة تم إقتراح التوصيات التالية: }
$$

- يجب على هشرفة تمريض الوحدة توزيع الرعاية التمريضية المقلمة المرضى طبقا لتكلفتها وإختيار التمريض المناسب التقديم ثلك الرعاية. - تقوم مشرفة تمريض الوحدة بمزج الخبرات المختلة فى جميع فترات العمل على مدار عب ساعة فى اليوم لتقديم آعلى جوده تمريضية ممكنة وضمان رضا المرضى. - يجب على إدارة المستشفى عند تسعير الخلمة التمريضية المرضى مراعاة تصنيفهم المرضى. 